\title{
CARACTERIZAÇÃO FITOQUÍMICA E ATIVIDADE ANTIBACTERIANA DO EXTRATO ETANÓLICO E DO ÓLEO ESSENCIAL DAS FOLHAS DE Cymbopogon citratus
}

\section{PHYTOCHEMICAL CHARACTERIZATION AND ANTIBACTERIAL ACTIVITY OF THE ETHANOLIC EXTRACT AND ESSENTIAL OIL OF THE LEAVES OF Cymbopogon citratus} \author{
Garcia Leandro $^{1}$ iD \\ ${ }^{1}$ Centro Universitário Dr. Leão Sampaio, Juazeiro do Norte, CE, Brasil. \\ ${ }^{2}$ Universidade Federal do Cariri, Juazeiro do Norte, CE, Brasil. \\ ${ }^{3}$ Universidade Federal do Ceará, Fortaleza, CE, Brasil. \\ *darciolsjr@gmail.com
}

Damires Inácio dos Santos $^{1}$ (D), Dárcio Luiz de Sousa Júnior ${ }^{2 *}$ (D), Maria de Fátima Guedes Monteiro $^{1}$ (D), Pedro Everson Alexandre de Aquino $^{3}$ (D) , Cícero Roberto Nascimento Saraiva $^{1}$ (D), Maria Karollyna do Nascimento Silva Leandro ${ }^{1}$ (D) Rakel Olinda Macedo da Silva ${ }^{1}$ (D) Lívia Maria

\section{RESUMO}

O Cymbopogon citratus é uma hortaliça bastante conhecida e utilizada, pertencente à família Paeceae, originada na Ásia e em alguns países tropicais, popularmente conhecida como Capim-santo é eficaz contra várias patologias como: asma, insônia, cólicas e ansiedade. O presente estudo teve como objetivo determinar o perfil fitoquímico do extrato etanólico e óleo essencial das folhas de $C$. citratus, assim como a atividade antibacteriana e modulatória frente às bactérias Escherichia coli, Staphylococcus aureus e Pseudomonas aeruginosa padrões e multirresistentes. Para a análise da atividade antibacteriana foi realizado o teste de microdiluição em caldo para determinação da concentração inibitória mínima (CIM), e a modificação da atividade dos aminoglicosídeos gentamicina e amicacina. Na caracterização fitoquímica foi observado a presença de compostos fenólicos no extrato como taninos e fenóis, além de apresentar alguns flavonoides. Os resultados obtidos da CIM em todas as bactérias testadas foi $\geq 1024 \mu \mathrm{g} / \mathrm{mL}$, tanto para o extrato quanto para o óleo essencial. O extrato etanólico, quando associado à amicacina e gentamicina, demonstrou um antagonismo, para as cepas $S$. aureus e $P$. aeruginosa, já quando se combinou o óleo essencial e os antibióticos, houve antagonismo apenas para $P$. aeruginosa, os demais resultados não foram significativos. Dessa forma, novos estudos com outros antibióticos devem ser realizados, visando buscar os efeitos ocasionados desse tipo de atividade combinada, pois, como nos dados obtidos, a redução do efeito do antibiótico pode dificultar o tratamento de diversas doenças.

Palavras-chave: Cymbopogon citratus. Modulação. Produtos naturais. Resistência bacteriana.

\section{ABSTRACT}

Cymbopogon citratus is a well-known and used vegetable, belonging to the Paeceae family, originated in Asia and in some tropical countries, popularly known as Capim-santo is effective against various pathologies such as asthma, insomnia, colic and anxiety. The present study aimed to determine the phytochemical profile of the ethanolic extract and essential oil from $C$. citratus leaves, as well as the antibacterial and modulatory activity against standard and multidrug-resistant Escherichia coli, Staphylococcus aureus and Pseudomonas aeruginosa bacteria. For the analysis of antibacterial activity, the broth microdilution test was performed to determine the minimum inhibitory concentration (MIC), and the modulatory activity of the aminoglycosides gentamicin and amikacin. In the phytochemical characterization it was observed the presence of phenolic compounds in the extract as tannins and phenols, besides presenting some flavonoids. The obtained results of the MIC in all tested bacteria were $\geq 1024 \mu \mathrm{g} / \mathrm{mL}$ for both the extract and the essential oil. The ethanolic extract, when associated with amikacin and gentamicin, showed antagonism to $S$. aureus and P. aeruginosa strains, but when the essential oil and antibiotics were combined, there was antagonism only to $P$. aeruginosa, the other results were not significant. Thus, new studies with other antibiotics should be carried out, aiming to seek the effects caused by this type of combined activity, because, as in the data obtained, the reduction of the antibiotic effect can hinder the treatment of various diseases.

Keywords: Cymbopogon citratus. Modulation. Natural products. Bacterial resistance. 


\section{INTRODUÇÃO}

As plantas medicinais vêm sendo utilizadas desde os tempos antigos e vem passando de geração para geração, principalmente de forma oral fazendo, portanto, parte da cultura populacional. As antigas civilizações perceberam com a utilização das mesmas que além de comestíveis, algumas possuíam poder curativo (CUNHA, 2003). O uso destas ervas serve como uma forma de escape terapêutico por possuírem um alto poder de cura, prevenção e tratamento, fazendo com que vários estudiosos se aprofundem em pesquisas sobre elas em busca de novas opções farmacológicas (HARAGUCHI; CARVALHO, 2010).

O uso inadequado dos antibióticos é o maior causador de resistência bacteriana (ZIMERMAN, 2010), as bactérias produzem enzimas que inativam os antimicrobianos impedindo que o fármaco chegue ao seu local de ação (GIBBONS, 2004). Bactérias como Escherichia coli está relacionada com resistência bacteriana, sendo conhecida como importante causador de infecções urinárias (MULLER; SANTOS; CORRÊA, 2008), Staphylococcus aureus que por sua vez é resistente as penicilinas (NOGUEIRA et al., 2009) causando infecção hospitalar e do trato urinário e pode produzir toxinas em alimentos contaminados (NASCIMENTO, 2013) e Pseudomonas aeruginosa que é um microrganismo considerado oportunista por causar infecções hospitalares (ALMEIDA, 2010).

Para se controlar a resistência bacteriana é muito importante a busca por novos antibióticos com novos mecanismos de ação, com isso, através de vários estudos e pesquisas sobre algumas plantas medicinais é observado efeito antibacteriano como uma ação que pode diminuir a resistência das bactérias (GURIB-FAKIM, 2006). Neste contexto, as plantas medicinais têm se sobressaído como alternativa para essa finalidade (TAKAHASHI; ESTHER, 2008).

Dentre estas plantas está o Capim Santo que é uma hortaliça de grande valor para a agricultura (MELHORANÇA FILHO et al., 2012). É uma espécie pertencente à família Paeceae, sendo muito saborosa e com um ótimo aroma (SCHNORR; MARCHIORETTO; SCHMITZ, 2010). Apresenta como característica folhagens finas, longas, aromáticas e ásperas (CARVALHO et al., 2005). O seu óleo essencial é usado para fabricação de vários produtos, como cosméticos e produtos químicos (COSTA et al., 2005). O chá desta hortaliça é utilizado contra a asma, ansiedade, cólicas abdominais, insônia, dentre outros (CARVALHO et al., 2005).

Portanto, na busca de novos alvos terapêuticos contra a resistência bacteriana, o presente estudo avaliou a atividade antibacteriana e modulatória do extrato etanólico e do óleo essencial da folha de Cymbopogon citratus frente a cepas de bactérias padrões e multirresistentes.

\section{MATERIAL E MÉTODOS}

\section{Coleta e identificação do material vegetal}

As folhas de Cymbopogon citratus foram obtidas na cidade de Brejo Santo, Ceará. Uma exsicata foi depositada no Herbário Caririense Dárdamo de Andrade Lima - HCDAL da Universidade Regional do Cariri - URCA, com registro de número 12.347.

\section{Extração do óleo essencial}

A extração do óleo essencial do Cymbopogon citratus (OECc) foi obtida a partir da hidro destilação, pelo método de arraste a vapor usando aparelho de Clevenger modificado. O procedimento se deu de forma que as folhas de Cymbopogon citratus foram colocadas em um balão de cinco litros, juntamente com 2,5 litros de água destilada e mantido em ebulição por duas horas. Após obter-se a mistura água/óleo no doseador, esta foi separada, tratada com sulfato de sódio anidro (Na2SO4) e filtrada para haver separação total entre o óleo e a água (CRAVEIRO; QUEIROZ, 1993). Este processo da destilação do óleo essencial foi executado no Laboratório de Química do Centro Universitário Leão Sampaio - UNILEÃO. 


\section{Preparação e obtenção do extrato etanólico}

Folhas ainda frescas de C. citratus ( $300 \mathrm{~g}$ ) foram trituradas e colocadas em um recipiente de vidro com tampa, contendo álcool etílico absoluto suficiente para submergir todo material vegetal $(500 \mathrm{~mL})$ por 72 horas, configurando o método de maceração simples. Após esse período, o material foi filtrado, o líquido obtido foi levado ao rotaevaporador para retirada do solvente e o extrato foi concentrado no banho-maria a $50{ }^{\circ} \mathrm{C}$ (BRASILEIRO et al., 2006).

\section{Fitoquímica preliminar}

A análise fitoquímica preliminar foi realizada utilizando a metodologia de Matos (1997), nesse caso, o extrato etanólico de $C$. citratus (EECc) foi diluído em álcool absoluto e separado em tubos de ensaio, nos quais são colocados reagentes específicos ( $\mathrm{NaOH}$ e HCL) e observado a mudança na coloração do líquido e a formação do precipitado, sugerindo assim, a presença de algumas classes de metabólitos secundários, como os compostos fenólicos mais comuns (FIRMO et al., 2014).

\section{Meio de cultura e microrganismos}

Brain Heart Infusion (BHI) foi o meio de cultura das cepas de escolha, preparado em concentração à 3,8\%. Os microrganismos utilizados nos testes foram linhagens padrão de Pseudomonas aeruginosa (ATCC 15442), Escherichia coli (ATCC 10536) e Staphylococcus aureus (ATCC 25923), e multirresistentes da espécie Escherichia coli (27), Staphylococcus aureus (358) e Pseudomonas aeruginosa (03), disponibilizadas pelo Centro Universitário Doutor Leão Sampaio e obtidas junto à Laborclin Indústria.

\section{Preparo e padronização dos inóculos bacterianos}

As linhagens foram inoculadas em caldo BHI, na concentração indicada à 3,8\% e ficaram incubadas durante 24 horas à temperatura de $35^{\circ} \mathrm{C}$ para propiciar o desenvolvimento das cepas bacterianas. Estas suspensões acrescidas de bactérias desenvolvidas foram diluídas na proporção de 1:10 em caldo BHI até o equivalente à $10^{5}$ céls/mL (COCKERILL et al., 2012).

\section{Determinação da Concentração Inibitória Mínima (CIM)}

Para concentração Inibitória Mínima (CIM) foi feito a distribuição na placa de microdiluição. Foram preparados tubos eppendorf @ contendo cada um $900 \mu \mathrm{L}$ de BHI $10 \%$ e $100 \mu \mathrm{L}$ da suspensão bacteriana, previamente diluída em solução salina até estabelecer 105 UFC. A placa foi preenchida no sentido numérico onde foi adicionado $100 \mu \mathrm{L}$ desta solução em cada poço (placa de 96 poços) e em seguida procedendo-se a microdiluição seriada com a solução de $100 \mu \mathrm{L}$ da substância testada, variando nas concentrações de 1024 a $8 \mu \mathrm{g} / \mathrm{mL}$. As placas foram levadas à incubadora por $24 \mathrm{~h}$ a 35 ${ }^{\circ} \mathrm{C}$. A revelação da CIM foi feita utilizando-se a Resazurina. A CIM é definida como a menor concentração na qual nenhum crescimento foi observado (JAVADPOUR et al., 2013).

Para leitura da CIM das amostras, foi preparada uma solução de Resazurina sódica (Sigma) em água destilada estéril na concentração de $0,01 \%$ (p/v). Após a incubação, $20 \mu \mathrm{L}$ da solução indicadora foi adicionada em cada cavidade e após o período de 1 hora à temperatura ambiente, foi possível realizar a interpretação dos resultados. A mudança de coloração azul para rosa devido à redução da Resazurina, indicou o crescimento bacteriano (MANN; MARKHAM, 1998; PALOMINO et al., 2002). 


\section{Atividade combinada do óleo essencial e do extrato etanólico com aminoglicosídeos}

A CIM de antibióticos da classe dos aminoglicosídeos (Amicacina e Gentamicina) foi realizada na presença e na ausência do extrato e óleo essencial de $C$. citratus em placas de microdiluição estéreis. Estes foram testados em concentração sub-inibitória (CIM/8). Toda a distribuição foi feita no sentido alfabético da placa. Em seguida, $100 \mu \mathrm{L}$ da droga Gentamicina ou Amicacina na concentração de $1024 \mu \mathrm{l} / \mathrm{mL}$ foram misturados ao primeiro poço, procedendo-se a microdiluição em série, numa proporção de 1:1 até a penúltima cavidade, reservando-se a última como controle. As concentrações de antimicrobianos variaram gradualmente de 1024 a $0.5 \mu \mathrm{g} / \mathrm{mL}$ (COUTINHO et al., 2008; SIEBRA et al., 2018).

\section{Análise estatística}

Os testes foram realizados em triplicata e os resultados expressos em média geométrica. Para análise estatística foi aplicada ANOVA two-way seguida do teste de Bonferroni, considerando significância de $\mathrm{p} \leq 0,05$, utilizando o software Graphpad Prism 7.0.

\section{RESULTADOS E DISCUSSÃO}

Na Tabela 1 são mostrados os resultados obtidos na prospecção fitoquímica preliminar, na qual foram revelados principalmente compostos fenólicos.

Tabela 1 - Fitoquímica preliminar do extrato etanólico de Cymbopogon citratus

\begin{tabular}{llccc} 
Fenóis e & Antocianinas e & Flavonas, \\
Taninos & Antocianidinas & $\begin{array}{c}\text { Chalconas e } \\
\text { Flavonóis e } \\
\text { Xantonas }\end{array}$ & Flavononóis & Saponina \\
& & & \\
\hline
\end{tabular}

$\begin{array}{llllll}+ & + & + & + & & +\end{array}$

Notas: + indica a presença do metabólito; - indica a ausência do metabólito.

Fonte: os autores.

No extrato etanólico há a presença de compostos químicos de interesse medicinal, a presença de Taninos e Fenóis é bem conhecida por contribuir com a atividade antioxidante, são estruturas polares, com alto peso molecular (AURICHIO et al., 2007; SOUSA et al., 2007).

As Antocianinas e Antocianidinas são muito encontradas em frutas e estão relacionadas com a coloração das plantas. São caracterizadas pela presença de 15 átomos de carbono na estrutura. Uma das características mais importantes dessa classe de compostos é que em soluções aquosas apresentam formas diferentes por conta do pH (MARÇO; POPPI; SCARMÍNIO, 2008). Chalconas e Auronas são subgrupos dos Flavonoides e esses compostos estão relacionados com a ação anti-inflamatória (COUTINHO et al., 2009).

As presenças de compostos fenólicos, como os flavonoides já eram esperados para esta espécie, segundo Boeira et al. (2020), os quais caracterizaram o extrato das folhas de C. citratus e obtiveram 31 fitoquímicos, dos quais em sua maioria era composta por esta classe de metabólicos secundários.

A atividade direta do extrato etanólico e óleo essencial obteve uma CIM $\geq 1024 \mu \mathrm{g} / \mathrm{mL}$, isso demonstra que não houve atividade antibacteriana intrínseca significativa, diante disso foi possível observar que o extrato etanólico e óleo essencial de $C$. citratus não possuem a capacidade de inibir o crescimento das bactérias testadas, sendo um fato relatado em estudos sobre Citrus limon L. e Sicana odorífera L. (CASTRO et al., 2010).

Possamai et al. (2019) analisaram, pelo método de disco-difusão, a CIM de três óleos essenciais de plantas aromáticas, inclusive a $C$. citratus, contra bactérias Gram positivas e negativas, isoladas de alimentos, e determinaram que, dentre os óleos, o de $C$. citratus teve a menor formação 
de halo de inibição, principalmente com a cepa do gênero Staphylococcus testada, corroborando com o presente trabalho, o qual não demonstrou atividade direta também para uma cepa deste gênero.

Diferentemente deste fato, no estudo de Boeira et al. (2020), os quais também analisaram a ação direta do extrato das folhas de $C$. citratus contra cepas bacterianas (Escherichia coli ATCC 25922, Salmonella enteritidis ATCC 13076 e Staphylococcus aureus ATCC 25923) pelo método de disco-difusão, houve uma inibição do crescimento bacteriano. Neste estudo também foi verificado que o óleo de $C$. citratus também é um bom agente conservante, resultados estes podem estar divergindo com o presente estudo devido a concentração usada ou metodologia empregada.

As Figuras 1 e 2 apresentam a atividade combinada do extrato etanólico e do óleo essencial, respectivamente, de $C$. citratus sob os aminoglicosídeos amicacina e gentamicina.

Figura 1 - Associação entre aminoglicosídeos e o EECc frente a bactérias multirresistentes

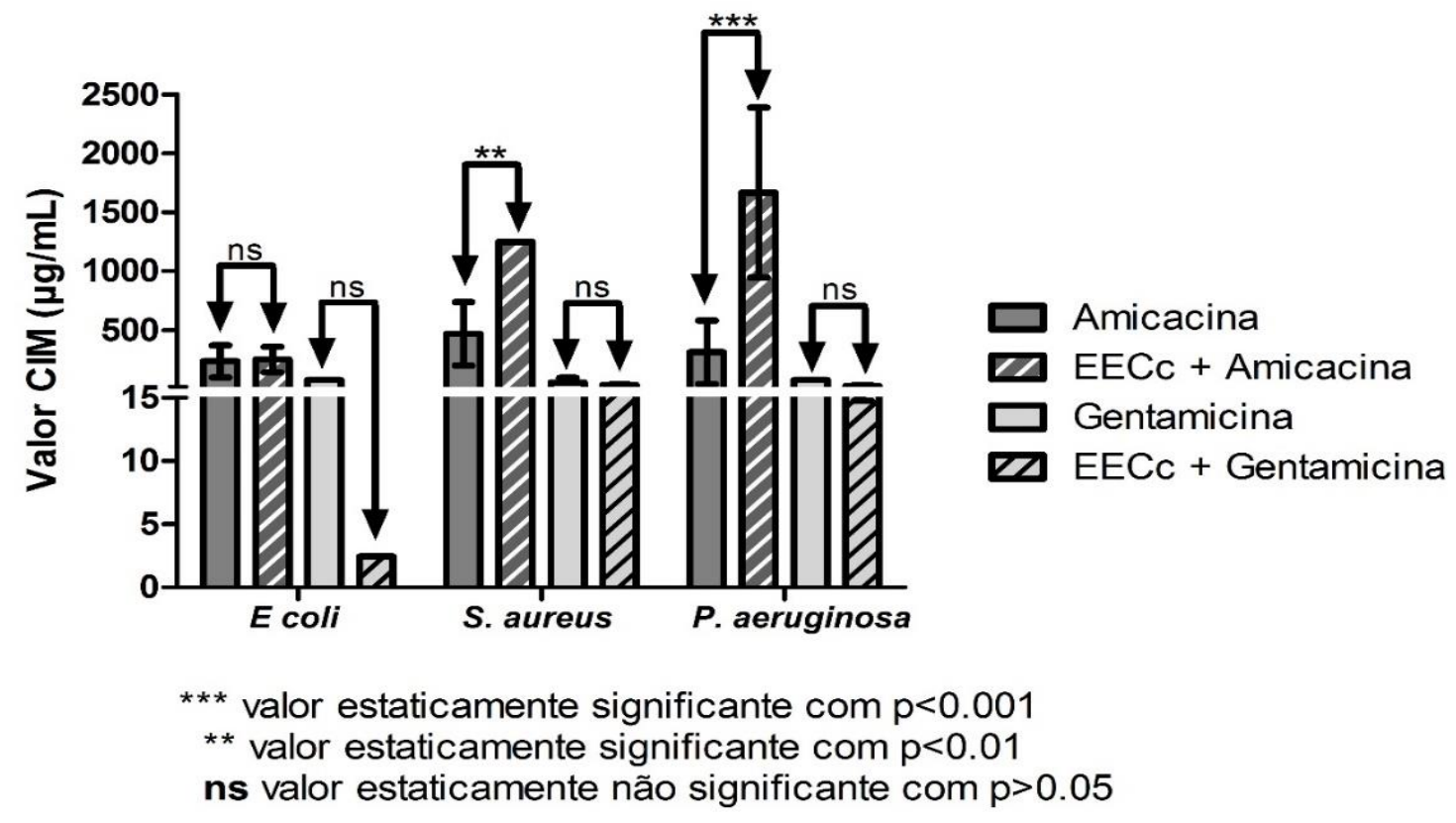

Fonte: os autores.

Figura 2 - Associação de aminoglicosídeos com o OECc frente bactérias multirresistentes

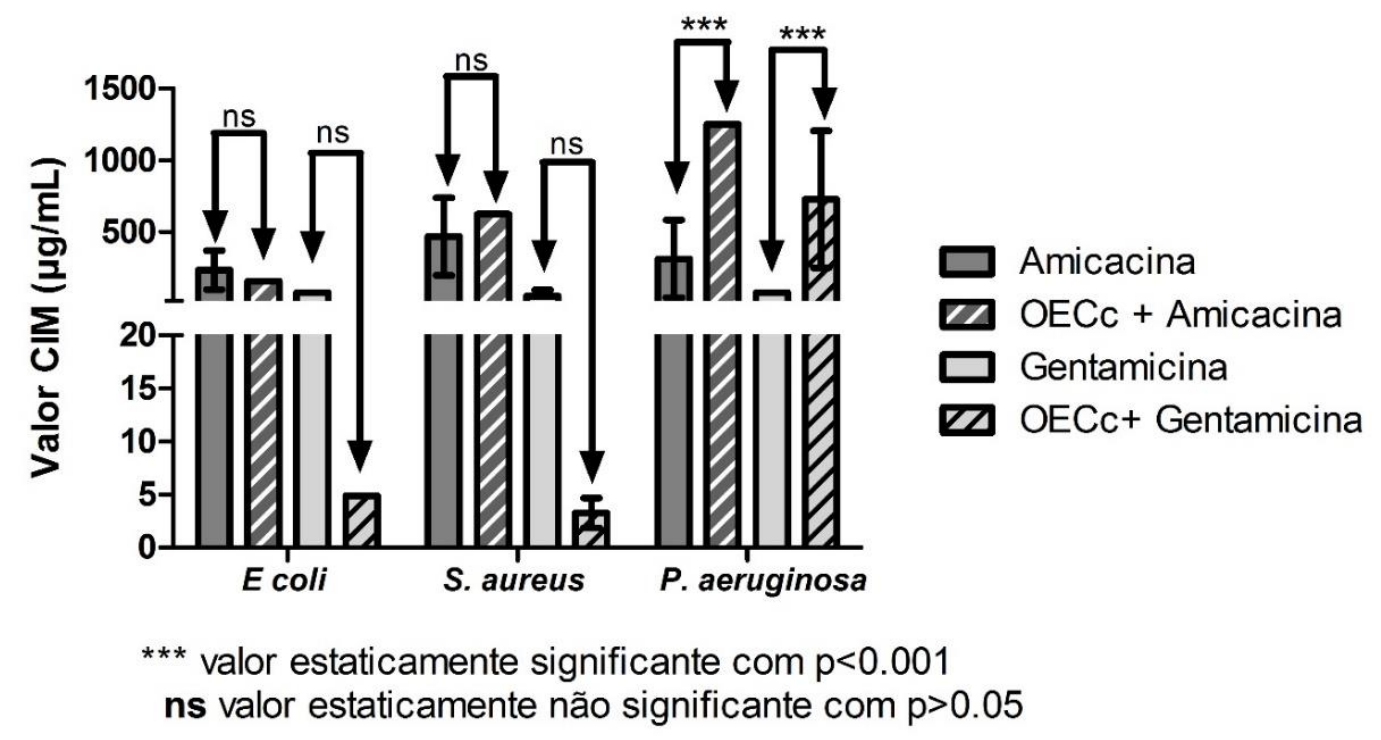

Fonte: os autores. 
As amostras de $C$. citratus que foram testadas, quando associados aos antibióticos amicacina e gentamicina não demonstraram resultados significativamente relevantes, inclusive houve um antagonismo com esses aminoglicosídeos para as cepas de $S$. aureus e P. aeruginosa com o EECc e também houve aumento da CIM desses dois fármacos para a cepa $P$. aeruginosa quando associados com o OECc, também confirgurando um antagonismo.

Gonçalves et al. (2019) testaram também a associação do óleo essencial de C. citratus com alguns antibióticos, inclusive a amicacina, contra cepas bacterianas (Staphylococcus aureus CCCDS013, Pseudomonas aeruginosa CCCD-POO4, Escherichia coli CCCD- E003), mas pelo método de disco-difusão, e constataram um sinergismo com a amicacina e o ceftriaxona, demonstrando que este óleo pode ter uma melhor ação quando combinado com outras classes de fármacos antimicrobianos ou por outros métodos de teste.

Interações negativas desta forma, como a combinação produto natural e fármaco agravar a ação do antibiótico, pode estar associada com componentes quelantes que se fazem presentes nos extratos e óleos essenciais de plantas medicinais, os quais podem fazer com que haja a diminuição dessa atividade, por se ligarem nas moléculas dos antimicrobianos e inativá-los (CRUZ et al., 2015).

\section{CONCLUSÃO}

Diante disto, é possível concluir que o extrato etanólico e o óleo essencial das folhas $C$. citratus não possuem uma atividade direta contra as bactérias multirresistentes testadas e que, ao serem associados a aminoglicosídeos como amicacina e gentamicina, ocasionam um antagonismo, aumentando a CIM inicial dos antibióticos necessária para inibir o crescimento dessas bactérias, como foi apresentado na avaliação in vitro. Dessa forma, é necessário que novos estudos com outros antibióticos sejam realizados, visando buscar uma atividade adjuvante ou uma ação intrínseca favorável, pois, como nos dados obtidos, a redução do efeito do antibiótico pode dificultar o tratamento de diversas doenças.

\section{REFERÊNCIAS}

ALMEIDA, R. G. Pseudomonas aeruginosa como indicador de qualidade de água. 2010. 14f. Trabalho de Conclusão de Curso (Licenciatura em Ciências Biológicas) - Universidade Metodista Izabela Hendrix, Belo Horizonte, 2010.

AURICCHIO, M. T. et al. Atividades antimicrobiana e antioxidante e toxicidade de Eugenia uniflora. Latin American Journal of Pharmacy, v. 26, n. 1, p. 76, 2007.

BRASILEIRO, B. G. et al. Antimicrobial and cytotoxic activities screening of some Brazilian medicinal plants used in Governador Valadares district. Revista Brasileira de Ciências Farmacêuticas, v. 42, n. 2, p. 195-202, 2006.

BOEIRA, C. P. et al. Phytochemical characterization and antimicrobial activity of Cymbopogon citratus extract for application as natural antioxidant in fresh sausage. Food chemistry, v. 319, p. 126553, 2020.

CARVALHO, M. C. et al., Rendimento da produção do óleo essencial de capim-santo submetido a diferentes tipos de adubação. Revista de Biologia e Ciências da Terra. v. 5, n. 2, p. 191-200, 2005.

CASTRO, R. D. et al. Atividade antibacteriana in vitro de produtos naturais sobre Lactobacillus casei. International Journal of Dentistry, v. 9, n. 2, p. 74-77, 2010. 
COCKERILL, F. R. et al. Methods for Dilution Antimicrobial Susceptibility Tests for Bacteria That Grow Aerobically, Clinical and Laboratory Standards Institute consensus process, 11. ed., 2012.

COUTINHO, H. D. et al. Enhancement of the antibiotic activity against a multiresistant Escherichia coli by Mentha arvensis L. and chlorpromazine. Chemotherapy, v. 54, n. 4, p. 328-330, 2008.

COUTINHO, M. A. S.; MUZITANO, M. F.; COSTA, S. S. Flavonoides: Potenciais agentes terapêuticos para o processo inflamatório. Revista Virtual de Química, v. 1, n. 3, p. 241-256, 2009.

CRUZ, A. J. F. et al. Avaliação da atividade antibacteriana e moduladora dos extratos metanólico e hexânico da folha de Allium cepa. Ciencias de la salud, v. 14, n. 2, p. 191-200, 2016.

COSTA, B. C. L. et al., Secagem e fragmentação da matéria seca no rendimento e composição do óleo essencial de capim-santo. Horticultura Brasileira, v. 23, n. 4, p. 956-959, 2005.

CRAVEIRO, A. A.; QUEIROZ, D. C. Óleos essenciais e química fina. Química nova, v. 16, n. 3, p. 224-228, 1993.

CUNHA A. P. Aspectos históricos sobre plantas medicinais, seus constituintes ativos e fitoterapia, 2003.

GONÇALVES, A. P. A. A.; PEREIRA, P. S.; GUERRA, M. S. B. Cymbopogon citratus: potencialização de antibióticos associados ao óleo essencial. Revista Saúde em Foco, n. 11, p. 507$515,2019$.

MELHORANÇA FILHO, A. L. et al. Avaliação do potencial alelopático de capim-santo (Cymbopogon citratus (DC) STAFF) sobre o desenvolvimento inicial de alface (Lactuca sativa 1), Ensaios e Ciência, v. 16, n. 2, p. 21-30, 2012.

FIRMO, W. C. A. et al. Estudo fitoquímico e avaliação da atividade antibacteriana de Lafoensia pacari (Lythraceae). UEPG Biológicas e da Saúde, v. 20, n. 1, p. 7-12, 2014.

GIBBONS, S. Anti-staphylococcal plant natural products. Natural Product Reports, v. 21, n. 2, p. 263-277, 2004.

GURIB-FAKIM, A. Medicinal plants: Traditions of yesterday and drugs of tomorrow. Molecular Aspects of Medicine, v. 27, n. 1, p. 91-93, 2006.

HARAGUCHI, L. M. M.; CARVALHO, O. B. O. Plantas medicinais. 1. ed. São Paulo, 2010.

JAVADPOUR, M. M. et al. De novo antimicrobial peptides with low mammalian cell toxicity. Journal of Medicinal Chemistry, v. 39, n. 16, p. 3107-3113, 1996.

LOPES, H. V. Antibióticos, resistência e novos mecanismos de ação. Revista Panamericana de Infectología, v. 11, n. 2, p. 67-68, 2009.

MANN, C. M.; MARKHAM, J. L. A new method for determining the minimum inhibitory concentration of essencial oils. Journal of Applied Microbiology, v. 84, n. 4, p. 538-544, 1998.

MARÇO, H. P.; POPPI, J. R.; SCARMÍNIO, S. I. Procedimentos analíticos para identificação de Antiocianinas presentes em extratos naturais. Revista Química nova, v. 31, n. 5, p. 1218-1223,2008. 
MATOS, F. J. A. Introdução à Fitoquímica Experimental. 2. ed. Fortaleza: UFC. 1997.

MULLER, E. V.; SANTOS, D. F.; CORRÊA, N. A. B. Prevalência de microrganismos em infecções do trato urinário de pacientes atendidos no laboratório de análises clínicas da Universidade Paranaense-Umuarama-PR. Revista Brasileira de Análises Clínicas, v. 40, n. 1, p. 35-37, 2008.

NASCIMENTO, A. L. D. R. Ação antimicrobiana do extrato de Eugenia uniflora L.(pitanga) sobre Staphylococcus aureus, Pseudomonas aeruginosa e Escherichia coli. 2013. 29f. Monografia (Trabalho de Conclusão de Curso) - Universidade Estadual da Paraíba, Campina Grande, 2014.

NOGUEIRA, P. S. F. et al. Perfil da infecção hospitalar em um hospital universitário. Revista Enfermagem UERJ, v. 17, n. 1, p. 96-101, 2009.

PALOMINO, J. C. et al. Resazurin microtiter assay plate: simple and unexpensive method for detection of drug resistance in Mycobacterium tuberculosis. Antimicrobial Agents and Chemotherapy, v. 46, n. 8, p. 2720-2722, 2002.

POSSAMAI, M. C. F. et al. In vitro bacteriostatic activity of Origanum vulgare, Cymbopogon citratus, and Lippia alba essential oils in cat food bacterial isolates. Semina: Ciências Agrárias, v. 40, n. 6 Supl.2, p. 3107-3122, 2019.

SIEBRA, A. L. A. et al. Potentiation of antibiotic activity by Passiflora cincinnata Mast. front of strains Staphylococcus aureus and Escherichia coli. Saudi Journal of Biological Sciences, v. 25, n. 1, p. 37-43, 2018.

SCHNORR, D. M.; MARCHIORETO, M. S.; SCHMITZ, P. I. Plantas medicinais usos populares tradicionais. Instituto Anchietano de Pesquisa/ UNISINOS, 2010.

TAKAHASHI, J. A.; ESTHER, M. F. L. Ocorrência e diversidade estrutural de metabólitos fúngicos com atividade antibiótica. Química Nova, v. 31, n. 7, p. 1807-1813, 2008.

TINTINO, S. R. et al. Atividade antibacteriana e moduladora in vitro de extrato metanólico e hexânico de Beta vulgaris spp. (Linnaeus). Revista Cubana de Plantas Medicinales, v. 21, n. 1, 2015.

ZIMERMAN, R. A. Uso indiscriminado de antimicrobianos e resistência microbiana. Ministério de Saúde, Brasil, n. 3, p. 1-12, 2010. 